\title{
Characteristics and Development Analysis of National Sports
}

\author{
Qiong Wang ${ }^{1}$, Chengmin Zhu ${ }^{2}$, Haijun Liu $^{3}$ \\ ${ }^{123}$ Zhaotong University, School of Physical Education, Zhao tong, Yunnan, 657000
}

KEYWORDS: Characteristics, Development Analysis, National Sports

\begin{abstract}
National sports culture is an important part of our social culture, it is under certain historical conditions, with the development of social life emerged. In the sports culture based on thousands of years of history, tradition, our national sports and cultural resources with the best of contemporary sports culture, a blend of modern social science, experienced heritage, innovation, development cycle, gradually toward a whole new look international, into the world.
\end{abstract}

\section{Introduction}

China is a multi-ethnic country. In the world of competitive sports and national sports culture is growing constantly blend today, how to correctly understand the value of national sports, according to its characteristics to create socialism with Chinese characteristics, sports, is a theoretical and practical significance.

China's sports industry is inseparable from the economic development of national sports industry. Due to China's rapid economic development led to the economic development of inland minority, so that national sports industry also has rapid economic development, but also promoted the development of China's traditional national sport. In recent years, ethnic minority areas to seize the opportunity of rapid development of the domestic economy, the full development of national sport, carry out a variety of sports activities, carry out large-scale sporting events and sports tourism, sports and trade, sports and entertainment, led the local tourism industry economic and trade development of the national sports industry in the economy, enriching the life of ethnic minorities and improve the living standards of ethnic minority people, strengthen the solidarity between nations. The "National Fitness Program" has provided for the development of national sports national sports industry and the guidance program, the positive development of minority sports, develop traditional ethnic sports, make the national sports industry to promote national economic development.

\section{The Concept of National Sports}

National sport is a reflection of humanity itself needs. It is human creativity in life and sports practice out of, tangible body shape, motor skills, sports equipment, material and spiritual intangible and social attributes related to the will, the concept and the times reflected displays various National Sports Features form. National Physical Culture and other cultures as a reflection of the times, national or ethnic characteristics and regulate people's behavior, but also affect human values.

\section{The Characteristics of Chinese National Sports}


Our national sport generated in the production needs of our people of all nationalities and survival, development of labor, combat, religious and recreational activities, and deeply rooted in the soil of our national culture, in the long historical process of development formed its own Features. Our national sport has the following characteristics:

From the point of view of cultural science point of view, the group's own human consciousness and self-awareness, the group I was with his group, to distinguish self and others, the competition is bound to exist. Due to competition consciousness, human activities in the competitive nature of sport also appeared in feature. Our national sport from a generation since it has this feature.

Cuju as the representative of the ancient ball sports more popular and popular in the Han Dynasty, ancient sports logo if maturing. It shows that football was not only a special racing venue, the equipment, there are certain rules racer, and organized various competitions, such as judges and other staff, with particular emphasis on the spirit of fair competition. Tang Dynasty door day "National Fusion brings quite healthy Takeo northern ethnic style, so characteristic of competitive sports of all ethnic groups have been developed, such as bold and vigorous competition fierce polo widely carried out. After the Song Mountain in by influence of Neo-Confucianism, Han nationality competitive features sports activities gradually reduced. but in private, preserved martial arts, dragon boat races and other sports games still full of competitive, especially in traditional ethnic sports, such as wrestling, wrestling, horse racing, Lamb, along the ice, archery is showing intense competitive features.

The characteristics and social life is also closely linked. National sport itself is the national customs, and production methods best explanation. As archery contests held in the traditional festival, commemorates the history of Xinjiang in Qing Dynasty ancestors moved from the northeast frontier defense, engaged in livestock production in Mongolia, Tajikistan, Kazakhstan, Tibetan and other ethnic groups, sports activities and more on weekdays from not open grasslands and horse riders riding trained skilled labor in the production of its natural environment and production breeds racing, Lamb, archery, polo and many other items Competitive riding day. Miao, Yi and Dong ethnic groups, mainly in the agricultural production in the peasant economy, the role of production exceeds the horse, so to retain the custom of bullfighting festival. Southern jungle minority hunter, bow making good efforts in the fight with the beast of trained skilled archery, a test of his spare time will inevitably have to each other, resulting in a lot of archery, shooting willow and other sports. Fishing mainly Hoche fork grass ball sports, but also reflects the link with production and life. Each nation's favorite dragon boat races, martial arts and other activities, are more prominently reflect the influence of the traditional culture of ethnic Sports.

National Sports in its long course of development,! ,, Gradually formed with Chinese people living environment, cultural heritage, human physiological and psychological adaptation phase, but also to meet the diverse needs of people at different levels of features. National Sports Geographically meat dish, its date of entry and competition in the form of their geographical location and national environmental and economic and cultural life is consistent; from the age of view, it can meet the needs of people of all ages. Although the nation to participate in sports activities, mostly young adults, but older mountain on their experience and reputation, we can act as a judge of the contest, and contest participants Angelus is the identity of the young guide, children can act as a learning By. Delicacies from gender, men can engage in the project horse racing, wrestling and other brave race and power, women can swing in the game, and tricks springboard flexible geometric items mouth. This feature not only with their physiological characteristics to adapt, but also with the respective responsible role in social life, adapt to the task; form from competition, the national sport can be divided into two kinds of individuals and groups break, such 
as dragon boat racing, tug of war, confrontation member of group competition. Wrestling, wrestling, horse racing is an individual race against.

Each item of National Traditional Sports day, often accompanied by beautiful and moving legends, or leads to a tragic epic poem, because the West with national culture and arts, such as dance, music linked, in the sound of singing and dancing, entertainment financial fitness as one, so as to achieve the Sports day.

\section{The Development of National Sports}

Current efforts to develop China's national sport is not big, but also unbalanced regional economic development, national development of the western region is relatively slow, inadequate investment in the main, the market, poor management, consumer awareness of the sports industry is relatively weak, the national sports industry the level is very backward, relatively closed ethnic areas, economic development is lagging behind, national sports development conditions are poor, sports funding reconstruction inadequate venues, facilities and additions are relatively scarce, to carry out some traditional national sport, still shabby conditions in carried out under difficult, some projects due to lack of space, the facility can not be carried out. To some extent, restricted the development of national sports industry is also disproportionate and China's economic development and the sports position in the international arena. To this end, the government should give the national sports industry preferential policies to guide the development of national industry sports, strengthening national sports tourism base, elongated National Sports Travel Industry chain, actively develop national sports equipment manufacturing industry, the introduction of capital and the strength of the national enterprises to expand the development of sports industry, expanding sources of funding national sports industry, tilted to the national sports industry in its tax policy. In addition to government departments to formulate national sports industry macroeconomic policies, it must also protect the national sports industry standardized management, the promotion of national sports tourism and sports equipment manufacturing industry with international practice, and vigorously promote and support the development of China's national sports industry.

National sports industry is an important part of the sports industry, the development of national sports industry will promote the development of China's sports industry, and to develop national sports industry can promote employment and stimulate the development of ethnic minority areas related industries. China's national sports national sports industry mainly tourism-oriented content industry, there is no pollution, low consumption of the environmental protection industry, has a unique national sports tourism resource, which is the beautiful natural scenery, the development of the sports industry and sports tourism Minority industry has a unique advantage in the ethnic areas, especially in these sports tourism market has brought unprecedented opportunities to our minority and tourism, has a wealth of natural resources and social and human resource development of sports tourism. Development of the sports industry, the development of national sports tourism, culture and entertainment can boost consumption and sports consumption and promote the development of the sports industry and related industries, and employment rate of ethnic minorities.

With China's economic development, people's living standards improve, the material life and the pursuit of spiritual and cultural life continues to improve, more people tend to regard the recreational sports fitness and entertainment characteristics and go on tour, with the National Sports Travel Industry to greater opportunities, but also make the national sports tourism has become a new hot spot and economic growth, people's desire to participate in the activities of local folk customs and national sport to watch is also increasingly strong. And our national sport is very rich characteristics of the project, is to meet the needs of the majority of domestic and foreign tourists. 
National sports features tour tourism projects have seasons: summer rafting, canoe race, canoe race; swimming, diving, swimming to catch ducks; autumn swing, springboard, pearl ball, shuttlecock ball, archery, tug of war, hold the stone, etc; in winter skating, skiing, horse racing, wrestling, crossbow; spring bullfighting, cockfighting, fighting sheep, fishing and so on. While also featuring various national sports can penetrate each other, introduce each other, communicate with each other to carry out, so that some characteristics of the project in national sports regardless of the season, regardless of nationality, regardless of geographical manner, enrich the connotation of national sports tourism, the promotion of national sports sustainable development of tourism.

China's national sports industry is not only the development and the development of national sport, not all national sports tourism as the main body, but to intensify efforts to develop national brands in national sports national sports equipment and special projects based on tourism, so that our national sports equipment industry to develop as quickly as possible, improve the technological content of the national sports manufacturing industry to expand domestic and international markets for China's national sports equipment share. However, the current size of China's national sports equipment manufacturer of small, low production level, is still in the family production status, to change the existing mode of production, improve the national sports equipment manufacturing, the government should fully support the introduction in industrial policy funds, the introduction of powerful enterprises, involved in the development and manufacture of national sports equipment, improve the manufacturing level national sports equipment, improve the national sports culture on the basis of the development of national sports equipment on, so that the national traditional Physical cultural industry and national Sports culture tourism industry, national sports equipment manufacturing industry closely combined, mutual promotion and mutual development, and actively explore the domestic and international markets, dig national sports products, strengthen market-oriented technology development, expand the scale of production in the national sports equipment manufacturing development of the market.

\section{Conclusion}

In summary, our national sport has a competitive nature, diversity, ethnic, sexual fitness and entertainment and other features, the development of China's sports undertakings, should be the development of China's national sports premise, based on the development of national sports to be effective, the broad absorption of foreign advanced sports culture, so that our sports development from the situation is neither one nor the blind xenophobia. Just seriously strengthen the organization and leadership of the national sport, the national sport of excavation, consolidation and improvement, national sport in our country will prosper, will surely stand erect in the world of sports.

\section{REFERENCE:}

[1] Annette R. Hofmaiin. Sport and Cultures [J]. Sportwissenschaft, 2005, 35(2):230-232

[2] Alan Warde. Cultural capital and the place of sport [J]. Cultural Trends, 2006,15(2-3): 107-122

[3] Belinda Wheaton. After Sport Culture[J]. Journal of Sport \& Social Issues, 2007, 31(3):283-307

[4] Burrows Lisette, McCormack Jaleh. School culture meets sport[J]. European Physical Education Review, 2011, 17(3); 301-312

[5] Claire Westall,Claire Westall. Marxism, cultural studies and sport [J]. Leisure Studies, 2010,29(2):227-229 